\title{
Kopuk pankreatik kanal sendromu tanı ve tedavisi: Tek merkez deneyimi
}

\author{
Diagnosis and treatment of disconnected pancreatic duct syndrome: Single center experience
}

\author{
Muhammet Yener AKPINAR' ${ }^{1}$, Bülent ÖDEMiş², Adem AKSOY², Mustafa KAPLAN², Orhan ÇOŞKUN² \\ Keçiören Eğitim ve Araştırma Hastanesi, ' Gastroenteroloji Bölümü, Ankara \\ Türkiye Yüksek Ihtisas Eğitim ve Araştırma Hastanesi, ${ }^{2}$ Gastroenteroloji Bölümü, Ankara
}

\begin{abstract}
Giriş ve Amaç: Kopuk pankreatik kanal sendromu pankreas kanalıın bütünlüğünün bozulmasıyla karakterizedir. Nadir görülen bu sendrom önemli bir morbidite ve mortalite nedenidir. Biz bu çalışmada kliniğimizde kopuk pankreatik kanal sendromu tanısı olan hastaların demografik özelliklerini, endoskopik retrograd kolanjiopankreatografi bulgularını ve bu hastaların aldıkları endoskopik tedavileri araştırdık. Gereç ve Yöntem: Bu çalışma Türkiye Yüksek ihtisas Hastanesi Gastroenteroloji Kliniği, Endoskopik Retrograd Kolanjiopankreatografi Ünitesinde Ocak 2010-Ocak 2017 tarihleri arasında kopuk pankreatik kanal sendromu tanısı alan hastalarla yapıldı. Kopuk pankreatik kanal senromlu hastalar etiyolojilerindeki nedenin pankreatit olup olmamasına göre ikiye ayrıldı. Kanal rüptürü 10 hastada olmak üzere en sık pankreas boynunda izlendi. Kanal rüptürünün baş ve boyunda olduğu hastalar distal grup, gövde ve kuyrukta olduğu hastalar ise proksimal grup olarak tanımlandı. Bulgular: Toplam 17 hastada kopuk pankreatik kanal sendromu vardl. Bu hastaların yaş ortancası 46 olup 14 hasta erkek, 3 hasta kadındı. Bu hastalara toplamda 27 endoskopik retrograd kolanjiopankreatografi seansı uygulandı. Etiyolojik neden olarak 9 hastada akut pankreatit, 2 hastada kronik pankreatit, 4 hastada travma ve 2 hastada ise insülinomadan dolayı yapılan pankreatektomi etiyolojik neden olarak izlendi. Akut pankreatit öyküsü olan hastaların 5 tanesi biliyer orjinliydi. 17 hastanın 15'inde psödokist, 1 hastada ise walled-off nekroz vardı. Kanal rüptürünün distalde ve proksimalde olduğu hastalar arasında endoskopik retrograd kolanjiopankreatografi işlem sayısı ve pankreatite yol açan etiyolojik nedenler karşılaştııılı ve anlamlı bir farklılık bulunmadı (sırasıyla $p=0,215, p=0,278)$. Sonuç: Çalışmamızda literatürle uyumlu olarak kopuk pankreatik kanal sendromlu hastalarda en sık etiyolojik neden olarak akut pankreatit izlendi. Hastalarımızın çoğunda kopuk pankreatik kanal sendromu boyun kısmında lokalize olup bu bulgu da literatürle uyumluydu. Bu sendroma uygun tanı konulamaması ve gerekli tedavinin yapılamaması hastaların morbidite ve mortalitelerinde artışa yol açacaktır.
\end{abstract}

Anahtar kelimeler: Endoskopik retrograd kolanjiopankreatografi, kopuk pankreatik kanal sendromu, tanı

\section{GíRiş}

Kopuk pankreatik kanal sendromu (KPKS) pankreasın ana kanalındaki epitelin nekrozu ve kanal bütünlüğünün bozulmasıyla karakterizedir. Kopuk pankreatik kanal terimi ilk olarak 1996 yılında kullanılmaya başlanmıştır (1). Pre-
Background and Aims: Disconnected pancreatic duct syndrome is characterized by the disruption. of the pancreatic duct. Although this syndrome is rare, it is an important cause of morbidity and mortality. Here we examined demographic characteristics, endoscopic retrograde cholangiopancreatography findings, and endoscopic treatment features of our patients with the diagnosis of disconnected pancreatic duct syndrome. Materials and Methods: This study was performed in the Endoscopic Retrograde Cholangiopancreatography Unit of the Türkiye Yüksek ihtisas Training and Research Hospital between January 2010 and January 2017. Patients who receive a diagnosis of disconnected pancreatic duct syndrome in an endoscopic retrograde cholangiopancreatography procedure were identified retrospectively. These patients were divided into two groups based on the location of their etiologic cause of pancreatitis. Patients with ductal distribution at the head and neck of the pancreas were defined as the distal group, whereas those with ductal distribution at the body and tail were defined as the proximal group. Results: Overall, 17 patients (median age 46, 14 males and 3 females) were included in the study. Twenty-seven endoscopic retrograde cholangiopancreatography procedures were performed in these patients. Acute pancreatitis was the etiologic cause in 9 patients. Other etiologic causes were chronic pancreatitis in 2 patients, trauma in 4 patients, and pancreatectomy in 2 patients. In acute pancreatitis, a biliary cause could be defined in 5 patients. Also, pseudocysts were diagnosed in 15 patients, whereas walled-off necrosis was diagnosed in 1 patient, and duct distribution was seen in the neck of the pancreas in 10 patients. The proximal and distal groups were not statistically different regarding both endoscopic retrograde cholangiopancreatography sessions and etiologic causes of pancreatitis $(p=.215, p=.278$, respectively). Conclusion: We found that acute pancreatitis is the most common etiologic cause of disconnected pancreatic duct syndrome and duct distribution was common at the neck of the pancreas similar to the literature. Both inappropriate diagnosis and delayed therapy can lead to increased morbidity and mortality in these patients.

Key words: Diagnosis, disconnected pancreatic duct syndrome, endoscopic retrograde cholangiopancreatography

valansı bilinmeyen bu sendromda ana pankreas kanalının bütünlüğünün anatomik olarak bozulması, kopuk kısmın her iki tarafında canlıı̆̆ını ve sekresyonlarını sürdüren iki ayrı pankreas dokusunun oluşmasına neden olur. Bu has- 
talarda kanal rüptürü parsiyel veya tam olabilir. Kopuk kanal, kanal rüptürü tam olduğunda verilen addır.

Etiyolojisinde sıklıkla akut nekrotizan pankreatit ve tramvaların yer aldığı bu sendromda kopuk alanın proksimalinde canlılığını sürdüren pankreas dokusu ve buradan salgılanan enzimden zengin sekresyonlar hastaların çoğunda morbidite ve mortalitede artışa yol açmaktadırlar (2). Sık izlenilmeyen bu sendromun tedavisi multidisipliner bir yaklaşım gerektirir. Biz bu çalışmada kliniğimizde kopuk pankreatik kanal sendromu tanısı olan hastaların demografik özelliklerini, (endoskopik retrograd kolanjiopankreatografi) ERCP bulgularını ve bu hastalara uygulanılan tedavileri araştırdık.

\section{GEREÇ ve YÖNTEM}

\section{Çalışma Dizaynı ve Hastalar}

Bu çalışma retrospektif olarak, Türkiye Yüksek İhtisas Hastanesi Gastroenteroloji Kliniği, ERCP ünitesinde Ocak 2010-Ocak 2017 tarihleri arasında KPKS tanısı alan hastalarla yapıldı. Belirtilen tarihler arasında ERCP raporlarında KPKS tanısı alan hastaların bilgilerine hastane otomasyon sistemi ve hasta dosyalarından ulaşıldı. KPKS tanısı literatürde önceden bildirildiği şekilde konuldu (2). Çalışma için gereken etik kurallara uyuldu.

\section{ERCP ve Kistogastrostomi Prosedürü}

Tüm ERCP ve transmural kist drenajı prosedürleri girişimsel endoskopide deneyimli ve yılda 1000 üzerinde ERCP yapan uzman endoskopistler tarafından yapıldı. ERCP ve transmural kist drenajı prosedürleri en az 8 saatlik açlık periyodu sonrasında gerçekliştirildi. Her iki işlem için video duodenoskop (Olympus TJF 260 or JF 260, Tokyo, Japan) kullanıldı. Pankreatik ERCP'de ilk olarak kılavuz tel ile pankreas kanalı bulundu. Daha sonra pankreatogram alınarak pankreatik kanal bütünlüğü ve kist içine olan iştirak değerlendirildi. Pankreatik sfinkterotomi saat 1 hizasında gerçekleştirildi. Transmural kist drenajı endoskopik incelemede mide veya duodenumdan, kistin en çok bası yaptığı yer görülerek gerçekleştirildi.

\section{Çalışma Verileri}

Kopuk pankreatik kanal sendromu tanısı alan hastaların bilgisayarlı tomografi veya manyetik rezonans görüntüleri incelenerek kopuk kanalla beraber var olan pankreatik ve peripankreatik sıvı koleksiyonları değerlendirildi. Hastaların etiyolojik nedenleri, pankreatogram bulguları, ERCP ile pankreasa yönelik olarak yapılan tedaviler ve var olan psödokistlerine yapılan tedavi verileri retrospektif olarak incelendi. KPKS'li hastalar etiyolojilerindeki nedenin pankreatit olup olmamasına göre ikiye ayrıldı. Kanal rüptürü- nün baş ve boyunda olduğu hastalar distal grup, gövde ve kuyrukta olduğu hastalar ise proksimal grup olarak tanımlandı.

\section{İstatistik}

İstatistiksel karşılaştırmalar SPSS16.0 programı yardımıyla yapıldı. Mann-Whitney testi gruplar arasındaki değişkenleri karşılaştırmada kullanıldı.

\section{BULGULAR}

Toplam 17 hastaya KPKS tanısı konulmuştu. Bu hastaların yaş ortancası 46 (16-71) olup 14 hasta erkek, 3 hasta kadındı. Bu hastalara toplamda 27 ERCP seansı uygulandı. Etiyolojik neden olarak 9 hastada akut pankreatit (AP), 2 hastada kronik pankreatit, 4 hastada travma ve 2 hastada ise insülinomadan dolayı yapılan pankreatektomi etiyolojik neden olarak izlendi. Akut pankreatit öyküsü olan hastaların 5 tanesi biliyer orjinliyken 4 tanesinde ise aşikar bir neden izlenmedi (Tablo 1). 17 hastanın 15'inde psödokist, 1 hastada ise walled-off nekroz (WON) vardı. Psödokistleri olan hastaların 6 tanesinde psödokistler kopuk pankreatik kanal proksimalinde kalan canlı pankreas dokusu ile ilişkili iken geri kalan 9 hastada ise psödokistler distal pankreas dokusu ile bağlantılıydı. WON olan hastada da bu lezyon distal pankreas ile bağlantılıydı.

ERCP ile hastaların hepsinde pankreas kanülasyonu yapımıştı, kanülasyon 14 hastada majör papilladan, 2 hastada minör papilladan ve 1 hastada ise aynı anda majör ve minör papilladan yapılmıştı. Kanülasyon sonrası 14 hasta-

Tablo 1. Hastaların demografik verileri

\begin{tabular}{lc}
\hline Değişkenler & Sayı \\
\hline Cinsiyet (erkek/kadın) & $14: 3$ \\
\hline Ortalama yaş & $46(16-71)$
\end{tabular}

\section{Kopuk kanal lokalizasyonu}
a) Proksimal (gövde:kuyruk)
b) Distal (baş:boyun)
$4: 3$
$0: 10$

\section{Etiyolojik neden}
a) Akut pankreatit

- Biliyer AP
$9(\% 52,9)$

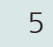
b) Kronik pankreatit
$2(\% 11,7)$
c) Travma
$4(\% 23,5)$
d) Cerrahiye sekonder
$2(\% 11,7)$

\section{Psödokist varlığı} 15 WON varlığı
1

AP: Akut pankreatit, WON: Walled-off nekroz. 
da pankreatik sfinkterotomi yapılmıştı. Pankreas kanalına stent 11 hastada konulmuştu; 8 hastada 5Fr, 3 hastada ise 7Fr çaplı stentler kullanılmıştı. Psödokisti olan hastaların 10 tanesinde psödokiste müdahale edilmişti. Bu hastaların 8'inde endoskopik kist drenajı uygulanırken 1 hastada hem endoskopik hem de perkütan kist drenajı, diğer bir hastada ise cerrahi nekrozektomi ve kist ekzisyonu yapılmıştı. Endoskopik olarak psödokiste müdahale edilen hastaların 8 tanesine kistogastrostomi yapılmışken bir hastaya kistoduodenostomi uygulanmıştı. WON olan hastaya da kistogastrostomi ve nekrozektomi yapımıştı (Tablo 2).

Kopuk pankreatik kanalın proksimalinde kalan canlı pankreasa yapılan müdahaleler ve bu kısmın akıbeti toplam 8 hastada değerlendirilebildi. Geri kalan 9 hastada çalışmanın retrospektif dizaynından dolayı bu bilgilere ulaşılamadı. 8 hastanın 6 tanesinde ana pankreastan kopuk olan gövde-kuyruk lokalizasyonundaki pankreas sekres-

Tablo 2. Hastalara uygulanan endoskopik tedaviler

\section{Değişkenler \\ Pankreas kanülizasyonu}

Sayı

17 hasta

$\begin{array}{lc}\text { a. Majör papilden } & 14 \\ \text { b. Minör papilden } & 2 \\ \text { c. Majör+minör papilden } & 1\end{array}$

\section{Pankreatik sfinkterotomi 14}

Pankreas kanalına konulan stent 11

a. $5 \mathrm{Fr}$

b. $7 \mathrm{Fr}$

Psödokiste uygulanılan endoskopik tedavi

a. Kistogastrostomi

8

b. Kistoduodenostomi

1

Kopuk kanal proksimalindeki canlı pankreas dokusunun morfolojik durumu ve uygulanan tedaviler ( 8 hasta)
a. Endoskopik kistogastrostomi
b. Cerrahi kistogastrostomi
c. Endoskopik ve perkütan kist drenajı
d. Pankreas rezeksiyonu
e. Intraabdominal pankreas fistülü

4

1

1

1 yonlarının devamı ile psödokist formasyonu oluşmuştu. Psödokisti olan bu 6 hastanın 4 tanesine endoskopik kist drenajı, 1 tanesine endoskopik ve perkütan kist drenajı ve diğer 1 tanesine ise cerrahi kistogastrostomi yapılmıştı. Geri kalan 2 hastada ise intrabadominal fistül oluşmuştu. Bu hastaların bir tanesinde ayrı pankreas dokusu için rezeksiyon uygulanmıştı. Diğer hastanın ise intraabdominal fistüle bağlı asit şikayeti belirgin olup bu hastanın fistülü endoskopik ve medikal tedaviye yanıt vermemişti.

Kanal rüptürünün distalde ve proksimalde olduğu hastalar arasında ECRP işlem sayısı ve pankreatite yol açan etiyolojik nedenler karşılaştırıldı. Bu iki grup arasında psödokist drenajı açısından da fark yoktu $(p=0,215)$. Distal kanal rüptürü olanların 7 tanesinde etiyolojide pankreatit izlenirken 3 tanesinde ise pankreatit dışı nedenler izlendi. Proksimal lokalizasyonlu hastalarda ise 4 hastada etiyolojik neden pankreatit iken 3 hastada pankreatit dışı nedenler izlendi. Her iki grup arasında etiyolojik nedenler açısından istatistiksel anlamlı bir fark izlenmedi $(p=0,278)$ (Tablo 3).

\section{TARTIŞMA}

Çalışmamızda literatürle uyumlu olarak KPKS hastalarda en sık etiyolojik neden olarak akut pankreatit izlendi. Hastalarımızın çoğunda KPKS boyun kısmında lokalize olup bu bulgu da literatürle uyumluydu. Fischer ve arkadaşlarının yaptıkları çalışmada bu hastaların yaş

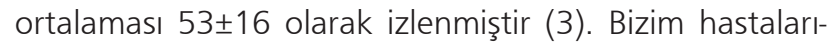
mızın yaş ortalaması da literatürde bildirilene benzerdi. Luna ve arkadaşları yaptıkları çalışmada kendi hastalarını kopuk olan ana pankreatik kanalın lokalizasyonuna göre baş-boyunda ve gövde-kuyrukta olanlar diye iki gruba ayırmışlardı (4). Çalışmada her iki grup arasında etiyolojik nedenleri, ERCP işlem sayılarını ve endoskopik iyileşmeyi karşılaştırmışlar ve gruplar arasında fark bulamamışlardı. Bizim çalışmamızda da bu çalışmayla uyumlu olarak proksimal ve distal grup arasında ERCP işlem sayıları ve etiyolojik neden açısından bir fark izlenmedi.

Kopuk pankreatik kanal sendromu farklı etiyolojilere bağlı olarak gelişen, pankreas kanalının bütünlüğünde bozulmayla karakterize bir sendromdur. Akut nekrotizan pankreatit geçiren hastaların \%30 kadarında ana pank-

Tablo 3. Proksimal ve distal grup arasında ERCP işlem sayısı ve etiyolojik nedenlerin karşılaştırılması

\begin{tabular}{|lccc|}
\hline Özellikler & Proksimal KPK & Distal KPK & p \\
\hline ERCP işlem sayısı & $1,71 \pm 7,65$ & $1,50 \pm 7,07$ & 0,515 \\
\hline Etiyolojik neden (pankreatit:diğerleri) & $4: 3$ & $7: 3$ & 0,278
\end{tabular}

KPK: Kopuk pankreatik kanal, ERCP: Endoskopik retrograd kolanjiopankreatografi. 
reatik kanalda kopukluk meydana gelmektedir. Kopuk pankreatik kanal sendromunda aşağı yönde kalan pankreas sekresyonları papilla majör yoluyla bağırsağa geçer. Kopukluğun yukarında kalan pankreas da sekresyonlarına devam etmektedir. Bununla beraber kopuk ana pankreas kanalından dolayı bu sekresyonlar peripankreatik alana, intraperitoneal veya retroperitoneal alana geçer. Enzimden zengin olan bu sekresyonlar pankreatik fistül, pankreatik asit, pseudodoanevrizma, psödokist ve pankreatoplevral fistül oluşmasına yol açabilir. Bu sendromda kanalın bütünlüğünün bozulmuş olan kısmı sıklıkla pankreasın boyun kısmında izlenir; pankreas boynunun kanlanmasının pankreasın diğer bölgelerine göre daha az olması bunda bir etkendir $(3,5)$. Hastalık etiyolojisinde sıklıkla akut pankreatit, travma, pankreas operasyonları ve kronik pankreatit yer almaktadır (6). Kopuk pankreatik kanal sendromu akut nekrotizan pankreatitten sonra sık görülmektedir. Akut nekrotizan pankreatitten sonra ana pankreas kanal bütünlüğünde bozulma sıklığını \%30-50 olarak bildiren çalışmalar vardır (7).

Sendromun tanısı ERCP, bilgisayarlı tomografi (BT) veya manyetik rezonans görüntüleme (MRG) ile konulmaktadır. Kopuk pankreatik kanal sendromu tanısı için belirtilen kriterlerden üçü de gereklidir: a) ERCP'de ana pankreas kanalının kesintili olduğunun gösterilmesi, b) BT veya MR gibi görüntüleme yöntemleri ile kesintinin olduğu kısmın proksimalinde canlı pankreasın gösterilmesi ve c) Konservatif medikal tedaviye yanıtsız pankreatik fistül, psödokist ve sıvı koleksiyonunun varlığı (8).

Kopuk pankreas kanal sendromlu hastaların tedavisi multidisipliner bir yaklaşım gerektirir. Bu sendromda oluşan psödokistler endoskopik veya perkütan drenaj işlemine dirençli olup pankreatik fistüller de sıklıkla persitandır. Bu özelliklerinden dolayı da cerrahi KPKS'na bağlı gelişen bu komplikasyonların tedavisinde sıkıkla başvurulan bir yöntem olmuştur. Endoskopik prosedürler psödokist ile mide veya duodenum arasında bir trakt oluşturarak başarı elde etmeye çalışır. Kist drenajı ile beraber pankreatik kanala kopuk alanı geçebilecek şekilde stent konulması son zamanlarda önerilen bir tedavi yöntemi haline gelmiştir. KPKS'lu hastaların psödokistlerine internal drenajın, psödokist küçülmesinde başlangıçta \%76'ya varan bir başarı oranı literatürde bildirilmektedir (9). Bununla beraber uzun dönem takiplerde hastaların \%50 kadarında psödokistlerde nüks izlenir (10). Psödokistlere uygulanan drenajla beraber pankreas kanalına konulan stent uzun dönem sonuçlarında nükslerde azalmaya yol açmıştır $(10,11)$. Rana ve arkadaşları, 30 hastalık serilerinde WON ve beraberinde KPKS olan hastalara kalıc transmural stent uygulamışlardır. Bu hastaların ortalama 20.4 \pm 12.2 aylık takiplerinde stent migrasyonu görülen hastaların dışında kalan 25 hastada semptomatik sıvı koleksiyonu görülmemiştir (12).

Sonuç olarak KPKS, tanı ve tedavisi özellik arz eden bir sendromdur. Bu sendroma uygun tanı konulamaması ve gerekli tedavinin yapılamaması hastaların morbidite ve mortalitelerinde artışa yol açacaktır. Çalışmamamızın en önemli eksikliği KPKS tanısı konulan hastaların uzun dönem tedavi sonuçlarının olmayışıdır. Hastanemizin üçünсü basamak referans bir hastane olması ve kimi zaman tedavi uygulanılan hastaların kalan tedavi ve takiplerini ikamet ettikleri şehirlerde yaptırmak istemeleri hasta takiplerini olumsuz olarak etkilemiştir.

\section{KAYNAKLAR}

1. Sandrasegaran K, Tann M, Jennings SG, et al. Disconnection of the pancreatic duct: an important but overlooked complication of severe acute pancreatitis. Radiographics 2007;27:1389-400.

2. Tann M, Maglinte D, Howard TH, et al. Disconnected pancreatic duct syndrome: imaging findings and therapeutic implications in 26 surgically corrected patients. J Comput Assist Tomogr 2003;27:577-82.

3. Fischer TD, Gutman DS, Hughes SJ, et al. Disconnected pancreatic duct syndrome: disease classification and management strategies. J Am Coll Surg 2014;219:704-12.

4. Pelaez-Luna M, Vege SS, Petersen BT, et al. Disconnected pancreatic duct syndrome in severe acute pancreatitis: clinical and imaging characteristics and outcomes in a cohort of 31 cases. Gastrointest Endosc 2008;68:91-7

5. Varadarajulu S, Wilcox CM. Endoscopic placement of permanent indwelling transmural stents in disconnected pancreatic duct syndrome: does benefit outweigh the risks? Gastrointest Endosc 2011;74:1408-12.

6. Lawrence C, Howell DA, Stefan AM, et al. Disconnected pancreatic tail syndrome: potential for endoscopic therapy and results of longterm follow-up. Gastrointest Endosc 2008;67:673-9.

7. Neoptolemos JP, London NJ, Carr-Locke DL. Assessment of main pancreatic duct integrity by endoscopic retrograde pancreatography in patients with acute pancreatitis. Br J Surg 1993;80:94-9.

8. Howard TJ, Rhodes GJ, Selzer DJ, et al. Roux-en-Y internal drainage is the best surgical option to treat patients with disconnected duct syndrome after severe acute pancreatitis. Surgery 2001;130:71421.

9. Nadkarni NA, Kotwal V, Sarr MG, et al. Disconnected Pancreatic Duct Syndrome: Endoscopic Stent or Surgeon's Knife? Pancreas 2015;44:16-22.

10. Devière J, Bueso $H$, Baize $M$, et al. Complete disruption of the main pancreatic duct: endoscopic management. Gastrointest Endosc 1995;42:445-51.

11. Larsen M, Kozarek RA. Management of Disconnected Pancreatic Duct Syndrome. Curr Treat Options Gastroenterol 2016;14:348-59.

12. Rana SS, Bhasin DK, Rao C, et al. Consequences of long term indwelling transmural stents in patients with walled off pancreatic necrosis \& disconnected pancreatic duct syndrome. Pancreatology 2013;13:486-90. 